\title{
Response to Poitrasson-Rivière and Murthy
}

We thank Poitrasson-Rivière and Murthy for their response to our Letter. ${ }^{1}$ While we can agree to disagree around statistical subtleties and fine aspects of a posteriori simulations used in their Editorial, we need to clarify that we do not use MAR clinically for primary interpretation, as the authors correctly observe the method has not yet been fully validated. As a result, the assertion that a technologist would be compelled for good clinical practice to remeasure discordant cases is unfounded. Although we disagree on specific details, we do all agree that we need to support one another in the pursuit of scientific rigor that can enable good clinical practice to improve health outcomes for our patients.

\author{
Robert deKemp,${ }^{a}$ Daniel Juneau, ${ }^{b}$ \\ George Wells, ${ }^{c}$ Rob Beanlands ${ }^{a}$ \\ ${ }^{a}$ Cardiac Imaging, University of Ottawa Heart Institute, Ottawa, ON, \\ Canada \\ ${ }^{b}$ Centre Hospitalier de L'Universite de Montreal, Montréal, $Q C$, \\ Canada \\ ${ }^{c}$ Cardiovascular Research Methods Centre, University of Ottawa \\ Heart Institute, Ottawa, ON, Canada
}

\section{References}

1. deKemp R, Juneau D, Wu K-Y, Wells G, Ruddy T, Beanlands R. On the roles of reproducibility, ethics, and statistical modeling in medical research. J Nucl Cardiol. 2021. https://doi.org/10.1007/ s12350-021-02592-z.

doi:10.1007/s12350-021-02639-1

Publisher's Note Springer Nature remains neutral with regard to jurisdictional claims in published maps and institutional affiliations. 